\title{
Breast Center Institute Buenos Aires, Argentina
}

\author{
Astrid L. Margossian Gustavo Jankilevich Ruth Weinberg Eduardo Gallo Juan Margossian \\ Breast Center Institute Buenos Aires, Argentina
}

The Breast Center Institute of Buenos Aires was established in September 2004 with the purpose of integrating breast disease management and research in a single institution. The Institute aims at excellence in breast cancer prevention, detection, and treatment through a personalized and multidisciplinary approach in keeping with the standards of the most advanced international breast centers. It offers a wide range of services to its patients:

- Early detection of breast disease.

- Genetic counseling on breast and ovarian cancer.

- Psychological support for breast cancer patients and multidisciplinary approach to patient counseling.

- Community educational lectures and workshops.

- Latest surgical and medical treatments.

- Aesthetic and oncoplastic surgery.

- Breast cancer research.

- Professional training and education.

The Breast Center Institute model of medical care and research is based on nearly 20 years of experience in managing breast disease, including more than 3,000 surgical operations and 4,000 diagnostic and interventional procedures.

Currently, the Breast Center Institute conducts approximately 1,000 new patient consults and 500 mammographies and breast ultrasounds per month, and our multidisciplinary team carries out approximately 500 breast surgeries per year. Patients referred to the Breast Center Institute typically come from a medium-high socio-economic stratus with access to quality medical care, such as reconstructive procedures or the latest cancer treatments. Nonetheless, the Breast Center Institute cooperates with public institutions through the GICMA organization (Grupo de Investigaciòn de Cancer de Mama en la Argentina), to also provide medical care and research participation opportunities to patients without health-care access in the private sector.

\section{Breast Surgery Department}

This department offers the latest surgical approach to breast cancer, with an emphasis on oncoplastic surgical techniques and offering patients a tailored surgical procedure to achieve the best possible aesthetics results. Sentinel node biopsy is offered to our patients as a standard surgical procedure. Further we offer image-guided breast surgical biopsies (mammography and ultrasound), of non palpable lesions for presurgical localization, breast conservation surgery, radioguided localisation (ROLL) of non-palpable breast lesions and simultaneous sentinel lymph node biopsy (SNOLL), skin sparing mastectomy with immediate reconstruction, and risk reduction mastectomy. In cooperation with the plastic and reconstructive surgery department, we perform several types of reconstructive surgery such as: expanders/implants, TRAM flap, latissimus dorsi flap, and combined techniques.

Our Breast Center Institute has already shown success in early detection of breast cancer since almost $50 \%$ of cases were diagnosed as non palpable lesions by image-guided breast biopsy (fig. 1).

Percutaneous procedures such as core biopsy and vacuum-assisted breast biopsy systems (mammotome) under stereotactic or ultrasound guidance, are also performed as standard preoperative techniques. Breast conserving surgery is done in $74.6 \%$ of breast cancer cases and mastectomy in $25.4 \%(\mathrm{n}=584$, fig. 2).

Risk reduction procedures such as bilateral skin sparing mastectomy with sentinel node biopsy and immediate reconstruction were started in 2005 in cooperation with the genetic counseling and reconstructive departments.

\begin{tabular}{ll}
\hline KARGER & ( ) 2007 S. Karger GmbH, Freiburg \\
Fax +497614520714 & Accessible online at: \\
$\begin{array}{l}\text { E-mail Information@Karger.de } \\
\text { www.karger.com }\end{array}$ & www.karger.com/brc \\
&
\end{tabular}




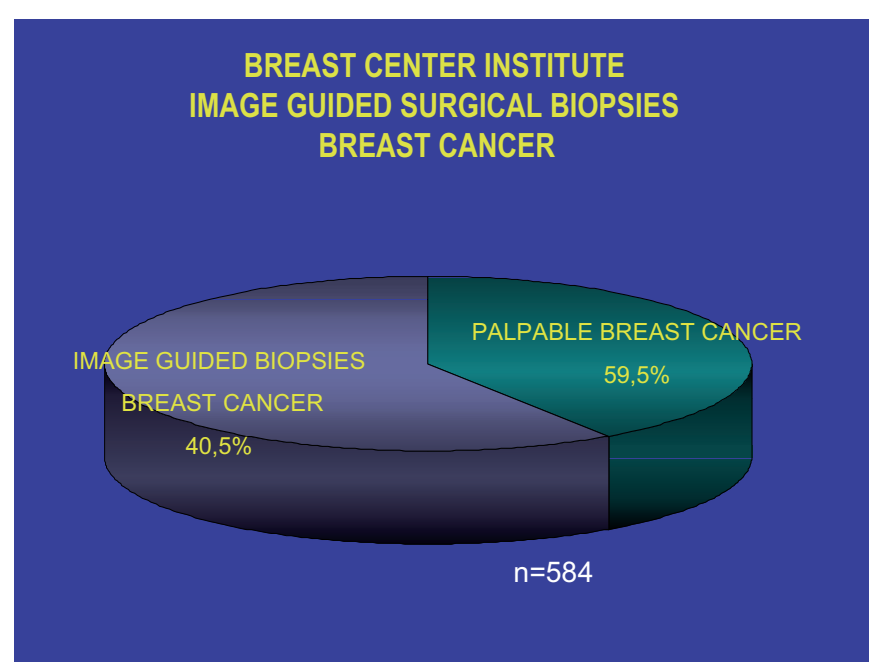

Fig. 1. Image guided surgical biopsies.

\section{Research and Education Department}

Since its foundation, the Breast Center Institute has been concerned with research and education as two important tools in the fight against breast cancer. Therefore, the Breast Center Institute has become an integral member and founder of GICMA, a collaborative group of oncologists, breast surgeons, pathologists, and gynecologists from the various member institutions (see below). The GICMA operates under the guidance of a board of directors to ensure full compliance with good clinical practice standards.

Community events are also an integral part of our breast cancer prevention and education efforts. They may consist of lectures on breast cancer, art exhibitions, or art workshops where patients, their family members, and health care professionals make use of artistic views of breast disease to advance educational objectives.

The Breast Center is currently involved in several clinical trials, many in collaboration with other national and international institutions around the world.

Thus, we believe that our Breast Center Institute has succeeded in establishing a pioneering integrated model of breast dis-

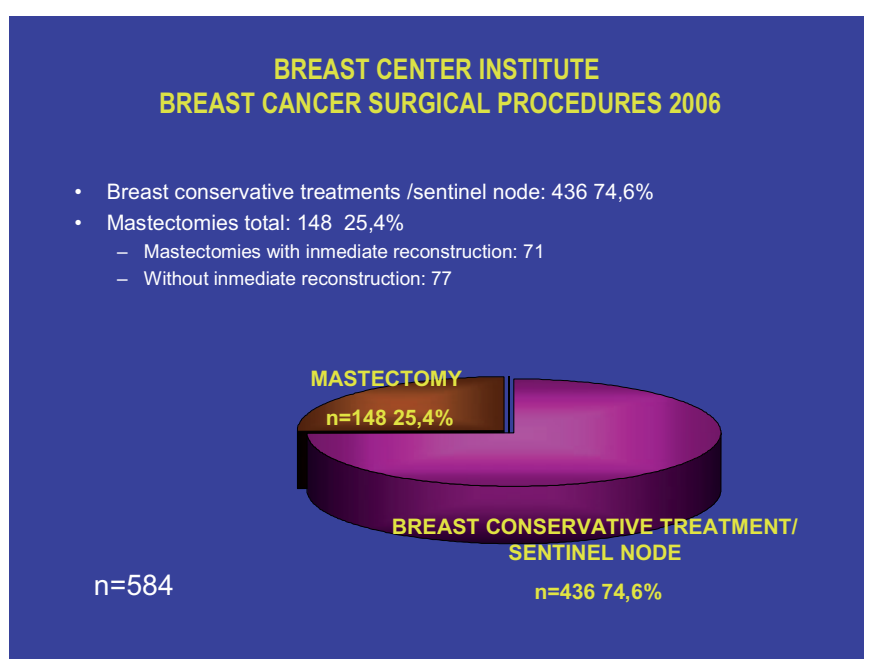

Fig. 2. Breast cancer surgical procedures.

ease management in Buenos Aires by bringing together all relevant specialties around patients with breast disease and expediting the delivery of medical care that they expect and deserve.

\section{Breast Center Staff}

Medical Director: Dra. Astrid Margossian. Clinical oncology: Dr. Gustavo Jankilevich. Breast surgery: Dra. Astrid Margossian, Dra. Ruth Weinberg, Dra. Carolina Kaufmann, Dr. Rodrigo Zlatkes. Genetic counselling: Dra. Carolina Kaufman. Reconstructive and esthetic surgery: Dr. Eduardo Gallo, Dra. Norma Fernández. Obstetrics and gynecology - reproduction: Dra. Andrea Marazzi. Obstetrics and gynecology: Dr. Leonardo Mezzabota. IRB Chairman: Prof. Dr. Juan Margossian.

\section{GICMA Argentinean Collaborating Institutions}

Breast Center Institute

Hospital Durand Buenos Aires

Hospital Interzonal de Agudos 'Eva Peron'

Universidad Abierta Interamericana

Centro Medico Austral 